\title{
Protein Glycation, Diabetes, and Aging
}

\author{
Peter Ulrich and Anthony Cerami \\ The Kenneth S. Warren Laboratories, 765 Old Saw Mill River Road, \\ Tarrytown, New York 10591
}

\begin{abstract}
Biological amines react with reducing sugars to form a complex family of rearranged and dehydrated covalent adducts that are often yellow-brown and/or fluorescent and include many crosslinked structures. Food chemists have long studied this process as a source of flavor, color, and texture changes in cooked, processed, and stored foods. During the 1970s and 1980s, it was realized that this process, called the Maillard reaction or advanced glycation, also occurs slowly in vivo. Advanced glycation endproducts (AGEs) that form are implicated, causing the complications of diabetes and aging, primarily via adventitious and crosslinking of proteins. Long-lived proteins such as structural collagen and lens crystallins particularly are implicated as pathogenic targets of AGE processes. AGE formation in vascular wall collagen appears to be an especially deleterious event, causing crosslinking of collagen molecules to each other and to circulating proteins. This leads to plaque formation, basement membrane thickening, and loss of vascular elasticity. The chemistry of these later-stage, glycation-derived crosslinks is still incompletely understood but, based on the hypothesis that AGE formation involves reactive carbonyl groups, the authors introduced the carbonyl reagent aminoguanidine hydrochloride as an inhibitor of AGE formation in vivo in the mid 1980s. Subsequent studies by many researchers have shown the effectiveness of aminoguanidine in slowing or preventing a wide range of complications of diabetes and aging in animals and, recently, in humans. Since, the authors have developed a new class of agents, exemplified by 4,5-dimethyl-3-phenacylthiazolium chloride (DPTC), which can chemically break already-formed AGE protein-protein crosslinks. These agents are based on a new theory of AGE crosslinking that postulates that $\alpha$-dicarbonyl structures are present in AGE protein-protein crosslinks. In studies in aged animals, DPTC has been shown to be capable of reverting indices of vascular compliance to levels seen in younger animals. Human clinical trials are underway.
\end{abstract}

\section{Introduction}

The nonenzymatic reaction of the amino groups of amino acids, peptides, and proteins with reducing sugars, ultimately resulting in the formation of complex brown pigments and protein-protein crosslinks, was first studied under defined conditions by L.C. Maillard in the early 1900s (Maillard and Gautier, 1912). Thus, it came to be known as the Maillard reaction. Ironically, Maillard's speculation that this process might be important in diabetes was an insight too far ahead of the technology capable of demonstrating it. Food chemists soon recognized the 
practical importance of the Maillard reaction in explaining brown color formation and loss of protein quality in cooked and stored foods. However, realization of the importance of Maillard-like reactions in vivo began in the mid-1970s. This started with our studics of hemoglobin Alc ( $\mathrm{HbAlc}$ ), a naturally occurring minor human hemoglobin that is elevated in diabetics. HbAlc was known to be a post-translational adduct of glucose with the $\mathrm{N}$-terminal valine amino group of the $\beta$ chain of hemoglobin, in which the glucose was thought to be attached via a nonenzymatically formed Schiff base structure. We found that measurement of the elevation of $\mathrm{HbAlc}$ in diabetics allowed assessment of the degree of glucose control integrated over several weeks (Koenig et al., 1976). However, the idea that $\mathrm{HbAlc}$ was a Schiff base was troubling, since Schiff bases are generally hydrolytically unstable. Subsequent work (Koenig et al., 1977) revealed that the carbohydrate in $\mathrm{HbAlc}$ was attached as a 1-deoxy-1-fructosyl residue to the $\mathrm{N}$-terminal valine nitrogen, derived from an initially formed Schiff base via a chemical transformation known as the Amadori rearrangement (Figure 1) (Hodge, 1955).

It was not until around 1980 that researchers began recognizing the significance of the complex, late-stage Maillard processes as mediators of the complications of diabetes (Bunn et al., 1978) and aging (Monnier and Cerami, 1981). Subsequently, proteins bearing Amadori product have come to be referred to as glycated proteins (distinguishing them from enzymatically glycosylated proteins), while the process of Amadori product formation is termed glycation. The laterstage, complex pigments and crosslinks formed from glycated protein during the in vivo Maillard reaction have come to be known as advanced glycation end-products, or AGEs (Bucala et al., 1992). Throughout the 1980s and 1990s, a large body of evidence has accumulated implicating AGEs as mediators of various complications of diabetes and aging. Pharmacological agents have been developed and placed in clinical trials to combat AGE processes in man. This chapter will summarize developments in this field and consider its future direction.

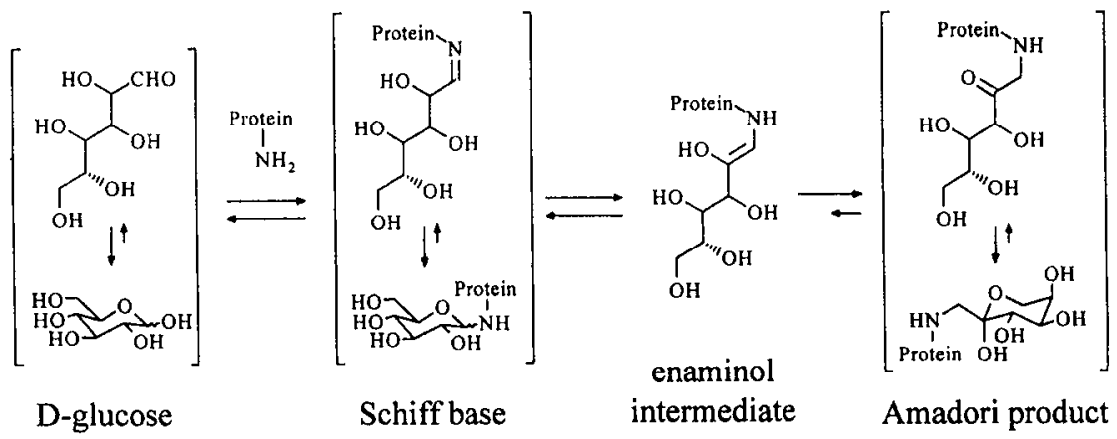

FIG. 1. Formation of the glucose-protein Schiff base and the Amadori rearrangement. 


\section{Chemical Background of Glycation and AGE Formation Under Physiological Conditions}

\section{A. THE MAILLARD REACTION}

Reducing sugars (e.g, glucose, fructose, galactose, mannose, ribose) and certain other carbohydrate relatives (e.g., ascorbic acid) are inherently reactive toward nucleophiles. Their reactivity toward nucleophilic nitrogen bases in protein underlies the Maillard reaction. Glucose is, in fact, the least reactive of the common sugars, perhaps leading to its evolutionary selection as the principal free sugar in vivo (Bunn et al., 1978). Nevertheless, glucose can react with a free amino group, such as the $\varepsilon$-amino group of a protein lysine residue, to form an adduct commonly referred to as a Schiff base. In a Schiff base, the aldehydic carbon-oxygen double bond of the sugar is converted to a carbon-nitrogen double bond with the amine (Figure 1). As is the case with free sugars, the open-chain, doublebonded form of the Schiff base adducts of hexoses or pentoses are thermodynamically disfavored with respect to the equilibrium cyclized pyranose or furanose forms, or glycosylamines (Paulsen and Pflughaupt, 1980) (Figure 1). To simplify mechanistic discussions of subsequent reactions, the adducts are frequently depicted as the more-reactive, open-chain forms. This convention will generally be followed here.

In the 1920s, Amadori showed that glucose-aniline Schiff bases could be converted to isomeric products that were not glycosylamine anomers (Amadori, 1925) but were subsequently found to be 1-anilino-1-deoxyfructose derivatives. It was not until the $1950 \mathrm{~s}$ that it was realized that Amadori products can form from aliphatic amines such as amino acids, not just from aromatic amines, and that the Amadori rearrangement was a key early step in the Maillard reaction (Hodge, 1955). The Amadori rearrangement of the Schiff base to the Amadori product is believed to occur via an intermediate, open-chain enol form (Figure 1).

Formation of the Schiff base from sugar and amine is relatively fast and highly reversible. Formation of Amadori product from the Schiff base is slower but much faster than the reverse reaction, so that the Amadori glycation product tends to accumulate on proteins. The Amadori rearrangement of a lysine-glucose Schiff base is thought to be facilitated if there is a histidine side-chain or another lysine amino group about $5 \AA$ from the amino group on which the Schiff base has formed, due to localized acid-base catalysis (Acosta et al., 2000). It is subsequent to the Amadori rearrangement that the less-well-understood, late-stage, advanced glycation processes begin. Despite considerable research by many laboratories, these slow, in vivo, AGE-forming processes are incompletely understood. It is known that the products include protein-protein crosslinking structures as well as various noncrosslinked structures. Many, but not all, of these products incorporate ultraviolet-visible and/or fluorescent chromophores. 
In recent years, it has become increasingly clear that $\alpha$-dicarbonyl compounds are key intermediates in the formation of AGEs. The Amadori product can break down via its enol form to reactive, free $\alpha$-dicarbonyl glyoxal compounds such as 3-deoxyglucosone, methylglyoxal, and glyoxal (Figure 2) (Thomalley et al., 1999, and references therein). These compounds are known to crosslink proteins and have been detected in vivo. The Amadori product also can dehydrate at the 4-position to yield a 1-amino-4-deoxy-2,3-dione (Amadori dione) (Figure 3) (Huber and Ledl, 1990; Chen and Cerami, 1993). This substance can further dehydrate at the 5-position to yield an unsaturated dione, the Amadori ene-dione (Figure 3) (Estendorfer $e t$ al., 1990). Evidence for crosslinking of proteins by the Amadori ene-dione, as depicted in Figure 3, will be discussed.

\section{B. FLUORESCENT AGE CROSSLINKS}

Reactions of $\alpha$-dicarbonyl compounds with basic amino acid residues or with Amadori intermediates are thought to be involved in formation of many of the known or suspected AGE crosslinking structures shown in Figure 4. Protein-protein crosslinks by such structures in vivo are thought to be responsible for a major share of the deleterious effects of AGEs in diabetes and aging. Along with brown color, fluorescence is one of the qualitative properties classically used to estimate<smiles>O=CC=O</smiles>

glyoxal<smiles>CC(=O)C=O</smiles>

methylglyoxal<smiles>O=CC(=O)CC(O)[C@H](O)CO</smiles>

3-deoxyglucosone

FIG. 2. Some $\alpha$-dicarbonyl glyoxal derivatives formed during glycation.

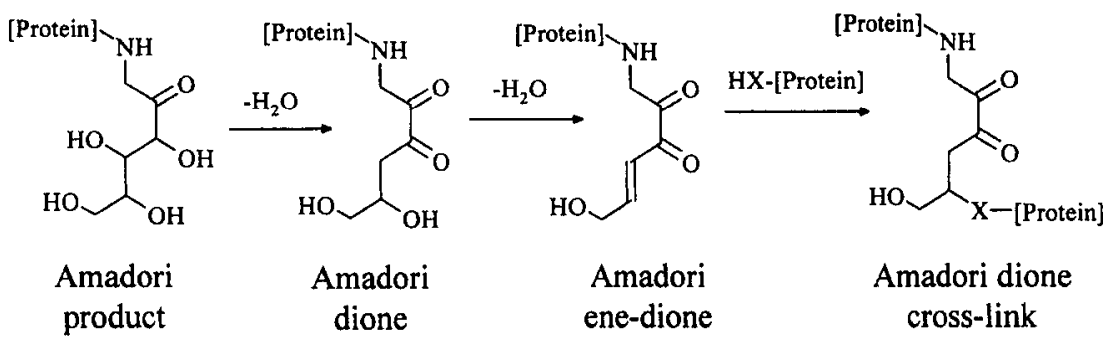

FIG. 3. Dehydration of the Amadori product to form Amadori dione and Amadori ene-dione and conjugate addition of a protein nucleophile to form a protein-protein crosslink. 
AGE formation. Many of the AGEs in Figure 4 were detected and isolated based on their fluorescent properties. The fluorescent AGE crosslink pentosidine was first isolated and identified from dura mater collagen and has since been identified in many tissues (Sell et al., 1991). Pentosidine is unusual in that it can be formed by the reaction of lysine and arginine with any of several carbohydrate precursors, including glucose, ribose, ascorbic acid, and 3-deoxyglucosone. Workers in a number of laboratories have isolated a variety of other fluorescent crosslinks in model reactions under physiological conditions: crosslines $A$ and $B$, vesperlysines A, B, and C; AGE-X1; pentodilysine; and pyrropyridine or FPPC. Of these, the crosslines (Obayashi et al., 1996) and vesperlysines (Tessier et al., 1999) have been detected in vivo.

\section{NONFLUORESCENT AGE CROSSLINKS}

Although their ease of detection makes them useful markers of AGE formation, the fluorescent AGE crosslinks are thought to account for only one percent or less of the total crosslinking structures formed under physiological conditions (Dyer et al., 1991). Thus, the major AGE structures responsible for protein-protein crosslinking in vivo are nonfluorescent structures that have not yet been conclusively identified. Recently, criteria other than fluorescence have been utilized to find new, nonfluorescent crosslinking AGE candidates that might represent the major in vivo AGE crosslink(s). These are depicted in Figure 5 and will be discussed individually in the following paragraphs.

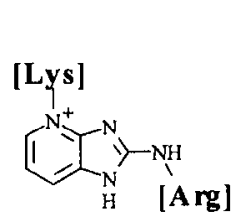

pentosidine

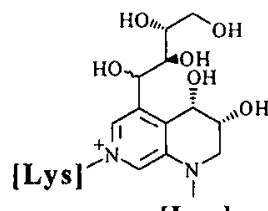

[Lys]

crossline

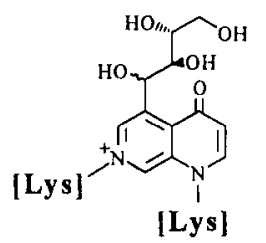

AGE-X1<smiles>O=C1CNc2cc[n+]([Al][Al])cc2C1</smiles>

[Lys]<smiles>Cc1c(O)cc2c(ccn2[Al])c1[N+]([AlH2])=[V]</smiles>

vesperlysine $A, B$<smiles></smiles>

vesperlysine $\mathrm{C}$<smiles>OCC(O)C1CN([AlH2])C2OC(N([AlH2])[AlH2])C2(O)C1</smiles>

FPPC

FIG. 4. Fluorescent AGE crosslinks formed under physiological conditions. [Lys] represents an E-norleucyl group (a desamino-lysine residue); [Arg] represents a $\delta$-norvalyl group (a desguanidinoarginine residue). 


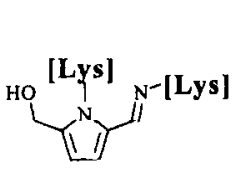

pyrraline imine

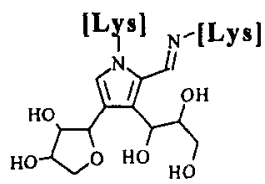

AFGP imine
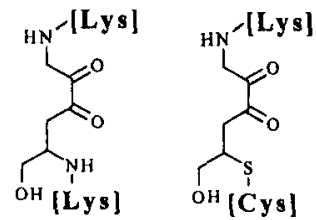

Some Possible Amadori dione cross-links

[His]

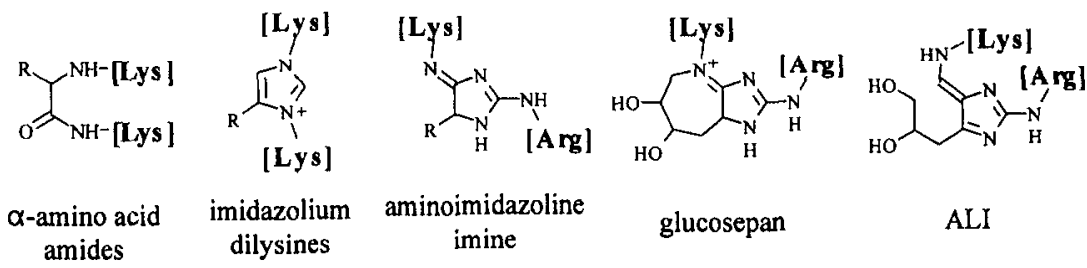

HIG. 5. Known and suspected nonfluorescent AGE crosslinks of physiological relevance. [Lys] represents an $\varepsilon$-norleucyl group (a desamino-lysine residue); [Arg] represents a $\delta$-norvalyl group (a desguanidino-arginine residue). [Cys] and [His] represent $\beta$-substituted alanine portions of cysteine and histidine residues, respectively.

\section{Imidazolium Dilysine Crosslinks}

Nonfluorescent imidazolium dilysine crosslinks, also known as GOLD/MOLD crosslinks, have been isolated from reaction of two molecules of glyoxal derivative with two lysine residues in vitro and also have been detected in vivo (Brinkmann Frye et al., 1998, and references therein). A related 2-acylimidazolium dilysine crosslink was proposed some years ago by our group, based on the isolation of presumed breakdown product 4-furanyl-2-furoylimidazole (FFI) from acid hydrolysis of AGE-modified bovine serum albumin (Pongor et al., 1984). Formation of FFI under these conditions is now thought to occur during isolation (Njoroge et al, 1988). However, AGEs of unknown structure crossreactive with FFI are detectable in AGE proteins in vitro and in vivo (Chang et al., 1985; Nakayama et al., 1988; Palinski et al., 1995). Such 2-acylimidazolium compounds are now known to be unstable toward hydrolytic loss of the acyl group, yielding 2-unsubstituted imidazolium derivatives, and thus are probable precursors of the imidazolium dilysine crosslinks (Al-Abed et al, 1996). The requirement of two moles of a glyoxal derivative for formation of a single imidazolium crosslink represents a mechanistic limitation on the role of imidazolium dilysine crosslinks in vivo. Moreover, formation of an imidazolium dilysine crosslink requires intermediacy of a double Schiff base of a glyoxal derivative with two lysine residues, which may alternatively rearrange to an $\alpha$-amino amide crosslink in a competing reaction (see below). Nevertheless, the imidazole dilys- 
ines are reported to be present at levels 10 - to 50 -fold higher than the fluorescent crosslink pentosidine in tissue proteins (Degenhardt et al., 1998).

\section{Alkyl Formyl Glycosyl Pyrrole (AFGP) Crosslinks}

With James Farmar, we isolated AFGPs (alkyl formyl glycosyl pyrroles) as noncrosslinking AGEs that form in the reaction of two sugar molecules with one alkylamine molecule representing a lysine residue (Farmar et al., 1988). The $\alpha$ positions of the side-chains attached to pyrrole ring carbons in AFGPs are susceptible to nucleophilic attack by thiols (Klein et al., 1992) and by lysine amino groups (J. Farmar and A. Cerami, unpublished data) (Figure 5), indicating that AFGPs are likely to be able to crosslink proteins. The requirement of two moles of sugar to form the AFGP structure and the fact that AFGPs are minor products in the absence of sulfite as a trapping agent (Farmar et al., 1988) suggest that AFGP crosslinks may be of limited importance in vivo.

\section{Pyrraline Crosslinks}

$N$-Alkyl-5-hydroxymethyl-2-pyrrolaldehyde, or pyrraline, is a monomeric AGE that may form on lysine residues in vivo (see below). The aldehyde of pyrraline can form a Schiff base with another amino group (Nissl et al., 1995) (Figure 5), which might lead to lysine-lysine crosslinking in vivo. However, this has not been demonstrated. Such crosslinks might be of limited stability with respect to hydrolytic reversion to their precursors.

\section{4. $\alpha$-Amino Acid Amide Crosslinks}

Sugars and Amadori compounds have been shown to react with primary amines to form $\mathrm{N}, \mathrm{N}^{\prime}$-dialkyl-alanine or -glycine amides (Figure 5). These represent a mode of lysine-lysine crosslinking that may occur in vivo; glyoxal derivatives from Amadori product breakdown are probable intermediates in their formation (Büttner et al., 1997). Such $\alpha$-amino amides may be difficult to isolate from proteins because they lack distinctive chromophores and are likely to be cleaved under protein hydrolysis conditions to give products (carboxymethyllysine and carboxyethyllysine) that are already known to form via other AGE-related processes in vivo (see below). Nevertheless, $\alpha$-amino acid amides are interesting contenders for a significant role in protein crosslinking in vivo.

\section{Aminoimidazoline Imine Crosslinks}

A new class of aminoimidazoline imine AGE protein crosslinks (Figure 5) has recently been reported. These are thought to be derived from reaction of arginine and an $\alpha$-oxoaldimine Schiff base of a lysine residue and glyoxal or methylglyoxal or 3-deoxyglucosone (Lederer and Klaiber, 1999, and references 
therein). The latter product can cyclize to a bicyclic crosslink the authors named glucosepan (Figure 5). These nonfluorescent crosslinks are potentially significant players in AGE crosslinking in vivo, as they require only one mole of carbohydrate-derived dicarbonyl component for their formation and they form relatively efficiently in model systems.

\section{Arginine-Lysine-Imidazole (ALI) Crosslink}

This recently described, nonfluorescent crosslink (Al-Abed and Bucala, 2000) (Figure 5) presumably derives from reaction of the Amadori dione (Figure 3) with an arginine residue. 'The ALI structure was isolated in a model system employing a model dipeptide (Arg-Lys), so that formation of the crosslink results in closure of a macrocyclic ring. ALI has not been reported as an intermolecular crosslink. It contains an enamine-like attachment that might be hydrolyzable. On the other hand, the authors showed that ALI has a potentially close immunochemical relationship with AGE structures on glucose-modified bovine serum albumin using an anti-AGE antibody that has been well characterized in prior studies in our laboratory (Makita et al., 1992). Thus, it is possible that ALI may be more important as an entropically stabilized, intramolecular protein crosslink than as an intermolecular crosslink; this question awaits further research.

\section{Amadori Dione Crosslink}

Conjugate addition of a nucleophilic protein side-chain to a protein-bound Amadori ene-dione would result in a protein-protein crosslink containing an $\alpha$-diketone structure in the linker (Figure 3). Figure 5 shows possible adducts for lysine, cysteine, and histidine. Precedent for conjugate addition of these amino acid residues to such an activated double bond is seen in the adduction of lysine, cysteine, and histidine to a structurally analogous site in the lipid peroxidation product 4-hydroxynonenal (Nadkarni and Sayre, 1995). We have postulated the existence of such an $\alpha$-dione-containing AGE crosslinking structure as shown in Figure 3. The current evidence for the existence of such crosslinks is that certain compounds we designed to destroy $\alpha$-dicarbonyl AGE intermediates were found to break a substantial proportion of the AGE crosslinks themselves, returning proteins experimentally crosslinked with AGEs to a noncrosslinked state (Vasan et al., 1996). The agents that do this are thiazolium salts, whose mechanism of action is based on the catalytic chemistry seen for the co-enzyme vitamin, thiamin, which has a thiazolium structure. These agents and their therapeutic effects will be discussed in detail later. One such agent, 4,5-dimethyl-3-phenacylthiazolium chloride, or DPTC, has been found to reverse certain sequelae of diabetes and aging in vivo (Wolffenbuttel et al., 1998; Asif et al., 2000). Other than the activity of agents like DPTC, there is as yet no direct chemical demonstration of the existence of the Amadori dione crosslink. It is also possible that agents such as 
DPTC might break other types of AGE crosslinks by as-yet-unknown mechanisms.

\section{NONCROSSLINKING, PROTEIN-BOUND AGE STRUCTURES OF IMPORTANCE IN VIVO}

Besides the crosslinking AGEs, which have profound effects on protein structure and function, a number of noncrosslinking AGE structures are found under physiological conditions. These may have deleterious effects as precursors of crosslinks or as biological receptor ligands inducing a variety of adverse cellular and tissue changes. [Such activities will be discussed in Section II.] Some of the more-important, noncrosslinking AGEs, shown in Figure 6, are described in the following paragraphs:

\section{Pyrraline}

Pyrraline is a pyrrole aldehyde AGE reportedly found in vivo (Hayase et al., 1989; Niwa, 1999). Pyrraline is derived from reaction of 3-deoxyglucosone with lysine residues. Pyrraline may form crosslinks between proteins, as discussed earlier.

\section{1-Carboxyalkyllysines}

AGEs in which a 1-carboxyalkyl group is attached to a free amino group of an amino acid residue, such as $N^{\varepsilon}$-(carboxymethyl)lysine (CML) and $N^{\varepsilon}$-(1-carboxyethyl)lysine (CEL), are found in proteins and in free form in vivo (Liardon et al., 1987; Krook et al., 1993; Ahmed et al., 1997). They may arise either from reaction of lysine residues with glyoxal derivatives (Glomb and Monnier, 1995) or from autoxidation of early-stage AGEs such as the Amadori product (Brinkmann Frye et al., 1998). Carboxymethyl derivatives of $\alpha$-amino groups of N-terminal amino acids are also possible, such as $\mathrm{N}$-carboxymethylvaline in hemoglobin (Cai and Hurst, 1999). CML formation seems to be a major pathway in vivo,

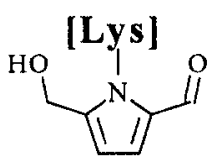

pyrraline<smiles>[R]C(N[AlH2])C(=O)O</smiles>

1 -carboxyalkyllysine

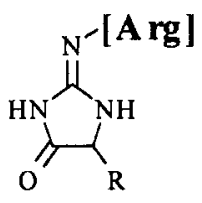

imidazolone A<smiles>[R]C1=N/C(=N\[141I][Na])NC1=O</smiles>

imidazolone B

FIG. 6. Some noncrosslinking AGEs of physiological relevance. [Lys] represents an $\varepsilon$-norleucyl group (a desamino-lysine residue); $|\mathbf{A r g}|$ represents a $\delta$-norvalyl group (a desguanidino-arginine residue). 
as urinary levels of CML in humans average 30 to 40 percent of levels of the lysine Amadori product (Knecht et al., 1991).

\section{Imidazolones}

The reaction of glyoxal or methylglyoxal (Paul et al., 1998, and references therein) or 3-deoxyglucosone (Niwa et al., 1997, and references therein) with the guanidino group of arginine can lead to formation of AGEs called imidazolones (Figure 6). These are structurally related to, but are probably not precursors of, aminoimidazoline imine crosslinks. Imidazolones of type A (Figure 6) undergo slow oxidation to imidazolones of type B. 3-Deoxyglucosone-derived imidazolone $\mathrm{A}$ and traces of $\mathrm{B}$ are found in vivo.

\section{E. FORMATION OF AGES ON DNA}

Like protein, DNA contains amino groups. The 2-amino group of guanosine is the most reactive. Reaction of glucose with guanosine yields $N^{2}$-glucopyranosylguanosine (Knerr et al., 1994) and a 1-carboxyalkyl derivative of $\mathrm{N}-2$ from glucose-derived 3-deoxyglucosone (Knerr and Severin, 1993). A 1-carboxyethyl $\mathrm{N}-2$ adduct of guanosine results from reaction with methylglyoxal (Papoulis et al., 1995) or glucose. Glyoxal and its derivatives also can form five-membered ring cyclic derivatives bridging $\mathrm{N}-1$ and the $\mathrm{C}-2$ amino of guanosine crosslink (Shapiro et al., 1969). None of these have been identified in in vivo sources. However, lysine and glucose-6-phosphate have been noted to form a reactive intermediate, not yet identified, that binds covalently to DNA (Lee and Cerami, 1987). Labeling studies show that the bound species contains the lysine component. The presence of AGEs on DNA causes unusual transpositional rearrangements (Lee and Cerami, 1990; Bucala et al., 1993a) [see Section II].

\section{F. ROLE OF OXIDATION IN FORMATION OF AGES}

Both the Amadori product and later-stage AGEs undergo autoxidation and have pro-oxidant effects on other molecules (Baynes and Thorpe, 1999). Enol structures such as the enaminol precursor of the Amadori product (Figure 1) or the 2,3-enol of the Amadori product may undergo one-electron oxidation to a radical species. Further oxidation of the radical can lead to fragmentation products, such as carboxymethyllysine (Brinkmann Frye et al., 1998). Alternatively, the AGE radical may abstract a hydrogen atom from a nearby biomolecule, converting it to a radical, leading to its autoxidation. The latter process is well demonstrated by the effect of glycation on lipoprotein complexes such as LDL (Bucala et al., 1994,1995). These effects will be discussed in more detail in Section II. 


\section{Biological Aspects of AGE Formation}

AGE precursors were first discovered in vivo on a hemoglobin. The glycation of hemoglobin increases its oxygen affinity and makes it more susceptible to oxidation (Bucala et al, 1992). However, effects of this type on soluble proteins are generally small and limited to the percentage of protein molecules actually glycated, which, in turn, depends on the half-life of the protein. Thus, most of the primary effects of AGEs leading to the complications of diabetes and aging are due to AGE formation on long-lived proteins. Collagen has a very low turnover rate and is a prime target. Especially damaging are the effects of AGEs on vascular collagen, which may contribute to atherosclerosis and coronary disease, kidney damage, retinal pathology, poor peripheral circulation, and other lesions. Lens crystallins are also a long-lived target, leading to cataracts. AGE damage to DNA may cause birth defects.

\section{A. EFFECTS OF AGE FORMATION ON CONNECTIVE TISSUE}

During formation of normal collagen fibrils, some collagen lysine residues and hydroxylysine residues are oxidized by lysyl oxidase, which converts their $\varepsilon$-amino groups to aldehydes. These aldehydes then undergo crosslinking reactions with lysine or hydroxylysine residues in adjacent collagen molecules in the fibrils. This process is self-limiting in that lysines in closely crosslinked collagen molecules are no longer sterically accessible to lysyl oxidase. Evolution has tailored this process to produce collagen fibrils with an optimal balance of strength and flexibility. Unfortunately, AGE crosslinking, being mediated by small molecules, is not subject to such limitations and can proceed even in mature collagen molecules. AGE-mediated overcrosslinking of connective tissue molecules (e.g., collagen molecules) to each other causes loss of bulk elasticity and flexibility and increased brittleness. Another example of damage to connective tissue by AGEs is the crosslinking of exogenous molecules to collagen, which can lead to pathological surface changes and overactivation of tissue repair mechanisms.

\section{Effects of AGE Formation on Vascular Connective Tissue}

Collagen has been shown to react with other collagen molecules or with other plasma proteins (e.g., albumin, immunoglobulin, low-density lipoprotein (LDL)), presumably through AGE crosslinking reactions (Brownlee et al., 1983). AGE crosslink formation in collagen contributes to diabetic circulatory complications such as vascular stiffening (Sims et al., 1996) and myocardial dysfunction (Avendano et al., 1999). The accumulation of the plasma proteins on structural proteins is believed to be a factor leading to the thickening of basement membranes and the development of atherosclerotic lesions (Bucala and Cerami, 1995). The possible involvement of AGE-modified LDL in this process is discussed below. 


\section{Effects of AGE Formation on Nonvascular Connective Tissue}

In both animals and humans, there is a significant correlation between the stiffening of structural collagen (e.g., tendon collagen and dura collagen) with age, the development of yellow-brown discoloration and fluorescence, and the levels of AGEs present. This can be mimicked by incubation of collagen sample with sugars in vitro (Yue et al., 1983; Kohn et al., 1984). These changes are accelerated in diabetes.

\section{B. EFFECTS OF AGE FORMATION ON SOLUBLE PROTEINS}

\section{Effects of AGE Formation in Lens Proteins}

Human lens crystallin proteins are very long lived, possibly lasting an entire lifetime. Although crystallins have evolved to retain optical clarity for an extended period, yellow-brown pigments with the spectral and fluorescent properties of AGFs do form in the lens as a function of age (Monnier and Cerami, 1983). These pigments can become so dark as to form cataracts, leading to blindness. In the normal lens, individual lens proteins associate via hydrophobic interactions to form aggregates of several million daltons. Substances such as glucose or cyanate can modify amino groups in crystallins, causing conformational changes. These changes expose previously buried sulfhydryl groups, which can then autoxidize to form intermolecular disulfide bonds (Monnier et al., 1979). The resulting disulfide-linked superaggregates of the aggregated lens crystallins can be of sufficient size to scatter light and produce a cataract. The importance of disulfide bonds in human cataract formation is indicated by studies showing that light scattering by cataracts in lens from older individuals can be significantly decreased by addition of reducing agents. However, a residual amount of protein crosslinking is present that is not disulfide related (Harding, 1973). AGEs may be directly implicated in this crosslinking.

\section{Effects of AGE Formation on Lipoproteins}

AGE modification of LDL can occur both on amino groups of the apoprotein component (Bucala et al., 1995) and on aminolipid components such as phosphatidylethanolamine (Bucala et al., 1993b). AGE formation on the apoprotein component can lead to crosslinking of LDL to the collagen layer of the blood vessel wall (Brownlee et al., 1983) and can increase the half-life of LDL in serum by blocking the recognition site for its receptor-mediated uptake (Bucala et al., 1995). This increases the probability of autoxidation of the lipid component (Bucala et al., 1993b). Like AGE formation, such oxidation of LDL can lead to loss of recognition by cellular LDL receptors and can induce its preferential uptake by macrophage scavenger receptors (Witztum and Steinberg, 1991). Macrophages 
attracted to AGEs on vessel wall collagen may thus accumulate modified LDL, leading to their conversion to foam cells that are thought to be central to the atherosclerotic process. The ability of AGEs present on LDL to initiate free-radical reactions (Bucala et al., 1993b) is of considerable importance because it provides an alternative to the hypothesis that metals are responsible for LDL autoxidation. Previous work on the initiation of LDL oxidation generally has implicated metal ions (e.g., iron, copper) as oxidation initiators. Unactivated oxygen does not normally react with most organic compounds. Through one-electron redox chemistry, iron or copper ions can induce the radical addition of oxygen to the olefinic bonds of unsaturated fatty acids to form hydroperoxides. Further reactions of these hydroperoxides with metals can form hydroxyl- and peroxyradicals that eventually cleave the fatty acids to form aldehydes. However, free (unchelated) metals usually are not present in significant amounts in vivo. The source of oxidation initiation for substrates like LDL has therefore been puzzling. The ability of AGEs to initiate such oxidative reactions in the absence of metals provides a new explanation for lipoprotein lipid peroxidation in vivo (Bucala et al., 1994).

\section{AGE Formation in $\beta$-Amyloid Plaques}

There is evidence that AGEs play a role in abnormal amyloid aggregation in Alzheimer's disease (AD). Amyloid plaque material like that from AD patients is also found in low quantity in age-matched human controls. Analysis of plaque material from both sources revealed that the plaque from AD patients had three times the AGE content per milligram amyloid as the amyloid from controls (Vitek et al., 1994). Since we know that AGE levels increase over time in normoglycemic individuals, one interpretation is that, in AD patients, a mechanism for removal of amyloid plaque is defective. The persisting plaque undergoes AGE crosslinking, gaining further resistance to proteolytic degradation and removal processes. In vitro studies have found that formation of insoluble, fibrillar aggregates from AGE-modified $\beta$-amyloid peptide was much faster than for control $\beta$-amyloid peptide.

\section{AGE-INDUCED OXIDANT DAMAGE}

The role of oxidative processes in the formation of carboxymethyllysine from the Amadori product, and the pro-oxidant effect of AGE formation on LDL, have been discussed in previous sections. These are part of a larger area of what have been termed "glycoxidation" reactions (Baynes and Thorpe, 1999) in which AGE formation processes and oxidative processes synergistically interact to produce deleterious tissue modifications, with the possible involvement of redox-active metals. These processes have some overlap with lipid peroxidation processes. The case of LDL oxidation already has been discussed, as has the chemical similarity 
of the Amadori ene-dione to the lipid oxidation product, 4-hydroxynonenal, both of which may crosslink proteins. Furthermore, glycoxidation and lipid peroxidation both can form glyoxal and other similar, small-molecule crosslink precursors.

\section{AGE-INDUCED DNA REARRANGEMENT}

As noted earlier, AGEs can form on DNA, particularly on guanine residues. The most-dramatic effect of AGE formation on DNA reported to date is the induction of unusual DNA rearrangements (Lee and Cerami, 1990,1991; Bucala et al., 1993a). Strains of $E$. coli that accumulate high levels of glucose-6-phosphate, which is particularly active in forming AGEs, demonstrate increased levels of the gamma delta transposition, which is the relocation of the transposable element gamma delta (Lee and Cerami, 1991). In mammalian cells, evidence has been found that AGE formation on DNA may be responsible for insertions containing repetitive sequences of the Alu family that have been found to disrupt human genes (Bucala et al., 1993a). The possibility that AGEs may induce genetic rearrangements in vivo has important implications; for example, as a possible cause of congenital malformations in infants of poorly controlled, insulin-dependent, diabetic mothers (Lee et al., 1995).

\section{E. EFFECTS OF AGEs IN FOOD}

Early studies showed that intravenous administration of exogenous, AGEmodified rat serum albumin (AGE-RSA) to rats caused complex vascular dysfunction, compared to rats receiving control RSA. These effects included significant increase in vascular permeability, enhanced mononuclear cell migration into subendothelial and periarteriolar spaces, and defective vasodilatory responses (Vlassara et al., 1992). Although ingestion of AGEs formed during the cooking or processing of food could be a potential source of exogenous AGEs, the possible importance of this was discounted due to the presumed poor absorption of food AGEs. However, it has since been found that food AGEs can be absorbed after eating. In diabetics with impaired renal function, food-derived AGEs with crosslinking activity can accumulate in serum to a significant degree (Koschinsky et al., 1997), implying that normal kidney function is important to protect from dietary AGEs.

\section{F. RECEPTORS FOR AGES AND THEIR POSSIBLE ROLE IN NORMAL REMOVAL OF AGES}

Scavenger receptors with an affinity for AGEs have been found on many cells such as macrophages, lymphocytes, and barrier cells (e.g., endothelial cells, mesangial cells) (Esposito et al., 1989; Skolnik et al., 1991). Phagocytic cells expressing these receptors can internalize and digest senescent, AGE-modified pro- 
teins, releasing AGE-modified peptides similar to those absorbable from food and normally excreted by the kidneys. The uptake of AGE proteins can signal the synthesis and release of certain cytokines and growth factors that can stimulate re-synthesis of proteins that have been phagocytically removed (Vlassara et al., 1988). If this process is not well regulated, serious problems can develop (e.g., tissue overgrowth). High levels of AGEs on matrix proteins in the diabetic kidney can induce mesangial cells to produce excessive amounts of matrix proteins, resulting in a thickened basement membrane incapable of sustaining normal kidney filtration processes (Makita et al., 1991).

\section{Pharmacological Intervention Against AGE Formation in Vivo}

The development of agents against AGE-related complications has followed two main approaches (Figure 7). First, inhibition of AGE formation processes by carbonyl-blocking agents such as aminoguanidine, and second, more recently, the cleavage of already formed AGE protein-protein crosslinks by dicarbonyl-breaking compounds like DPTC.

\section{A. PHARMACOLOGICAL INHIBITION OF AGE CROSSLINK FORMATION}

In the early 1980 s, when it became clear that advanced glycation reactions were a potential cause of complications of diabetes and aging, we began to think

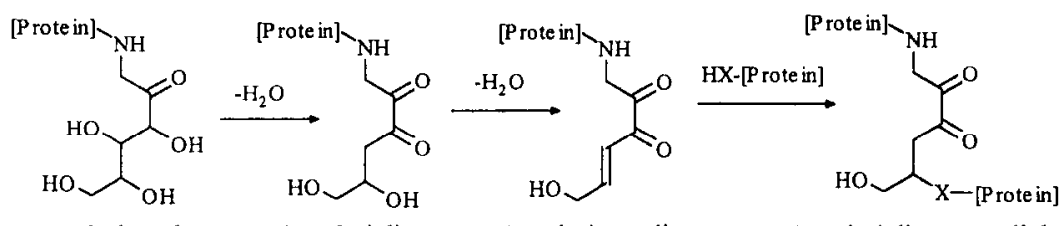

Amadori product (glycated protein)

Amadori dione

Amadori ene-dione
Amadori dione crosslink

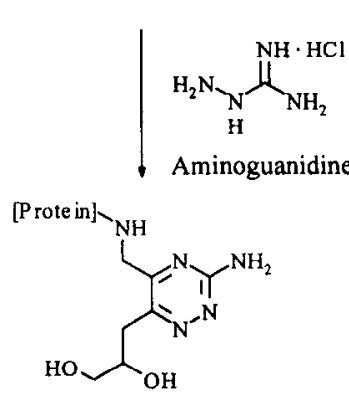

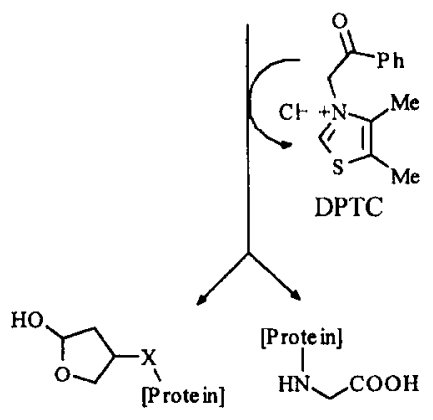

FIG. 7. Possible sites of post-Amadori crosslink prevention by aminoguanidine and crosslink cleavage by DPTC (ALT-711). 
about ways to interfere with this process pharmacologically. Unfortunately, little was known at that time about the pathways of AGE formation in the Maillard reaction in vivo. We focussed our attention on the structure of the Amadori product. We reasoned that the ketone group of the 1-amino-1-deoxyfructose residue in the Amadori product was the key to subsequent AGE-forming reactions and that chemical deactivation of this ketone group would prevent AGE formation. We therefore sought to identify an agent that would react rapidly with ketones, rendering them chemically inert, while being relatively nontoxic. A number of factors focussed our attention on aminoguanidine. It is a low-molecular-weight, highly nucleophilic compound that very readily reacts with ketones and aldehydes. There are some published reports of its experimental use in humans for unrelated purposes, without significant side-effects. We therefore selected aminoguanidine for preclinical study (Brownlee et al, 1986). In the intervening years, research in our laboratory and in others around the world has shown the effectiveness of aminoguanidine in inhibiting AGE formation in vivo in a wide variety of systems and tissues (Table I). As discussed earlier, $\alpha$-dicarbonyl intermediates, and not the initial Amadori product, are now believed to be the targets of aminoguanidine inhibition.

TABLE I

Effect of Aminoguanidine on Diabetes-related Complications or AGE Formation in Vivo

Nephropathy

- Inhibition of basement membrane thickening (Ellis and Good, 1991)

- Prevention of albuminuria (Soulis-Liparota et al., 1991)

- Stabilization of IGF system (Bach et al., 2000).

Retinopathy

- Normalization of endothelial cell proliferation (Hammes et al., 1991)

- Restoration of retinal nNOS neurons (Roufail et al., 1998)

Vasculopathy

- Reduction of vasodilatory impairment (Vlassara et al., 1992)

- Preservation of vascular elasticity (Huijberts et al., 1993)

- Improvement of erythrocyte deformability (Brown et al., 1993)

- Anti-atherogenic effect (Panagiotopoulos et al., 1998)

Neuropathy

- Retention of nerve conduction velocity (Kihara et al., 1991; Miyauchi et al., 1996) 
A phase III clinical study of aminoguanidine (also known by the generic name, pimagedine) in diabetic patients was completed recently. Patients in the study showed significantly decreased LDL levels, decreased urinary albumin levels (an important indicator of diabetic nephropathy), decreased progression of retinal degeneration, and a trend toward prevention of loss of kidney function. Further trials will be necessary before aminoguanidine can be approved for clinical use.

\section{B. PHARMACOLOGICAL CLEAVAGE OF AGE CROSSLINKS}

Like the outcome of the Diabetes Control \& Complications Trial, the activity of aminoguanidine against diabetic complications is another important piece of evidence supporting the AGE theory of diabetic complications in humans. However, there is a major limitation to the utility of AGE formation inhibitors like aminoguanidine: they cannot affect already-formed AGE damage, particularly crosslinking. A drug that could break already-formed crosslinks is a more desirable goal, as it would allow direct restoration of AGE-damaged tissue to its original functionality, without relying on the body's much-slower, more-problematical removal and repair mechanisms. In the absence of a clear understanding of the specific chemical mechanisms of AGE crosslink formation, developing such a drug seemed an unattainable goal. However, in the course of designing a new class of AGE inhibitors, we devised a new theory of AGE crosslinking that suggested the possible existence of crosslinking structures that could be chemically broken.

Alpha-dicarbonyl compounds such as $\alpha$-oxoaldehydes (glyoxal derivatives) (Figure 2) and their Schiff bases are thought by many researchers to be key reactive intermediates in AGE formation in vivo. Somewhat less studied have been $\alpha$-dicarbonyl (diketone) intermediates of the $\Lambda$ madori dione pathway, resulting from dehydration of the Amadori product with the amino acid still attached (Figure 3). We noticed that the Amadori ene-dione contained a structural motif that would allow it to form a protein-protein crosslink via conjugatc addition of another nucleophilic side-chain to the carbon-carbon double bond in a Michael reaction (Figure 3). Such a conjugate addition by lysine, histidine, and cysteine residues has been reported for a chemically related structural motif in the lipid peroxidation product, 4-hydroxynonenal (Nadkarni and Sayre, 1995). The resulting Amadori dione AGE crosslink structure (Figures 3 and 5) would contain an $\alpha$-diketone.

We designed a new class of anti-AGE agents that contained a thiazolium structure, which could chemically break $\alpha$-dicarbonyl compounds (e.g., glyoxals, $\alpha$-diketones) by cleaving the carbon-carbon bond between the carbonyls. We thought that these agents would inhibit $A G E$ processes by destroying glyoxal derivatives and the Amadori diones. However, it was difficult to assess the 
prospects for a major physiological role for $\alpha$-dicarbonyl-containing crosslink structures that would be cleavable by these agents. Thus, it was a pleasant surprise when we found that the thiazolium agent 3-phenacylthiazolium bromide (PTB) was able to cleave a major proportion of AGE crosslinks formed under physiological conditions (Vasan et al., 1996). Subsequently, we have developed a more-stable and more-active derivative, 4,5-dimethyl-3-phenacylthiazolium chloride (DPTC), which has shown a variety of promising effects in preclinical studies. For example, at a dose of $1 \mathrm{mg} / \mathrm{kg} /$ day for $1-3$ weeks in streptozocin-diabetic rats, DPTC reversed the large artery stiffness resulting from diabetes, as assessed by the criteria of systemic arterial compliance, aortic impedance, and carotid artery compliance. DPTC also reduced the diabetes-related increased crosslinking of tail tendon collagen, as measured by susceptiblilty to proteolytic degradation (Wolffenbuttel et al., 1998). In a more-recent study in aged dogs, invasive monitoring was used to measure end diastolic pressure and volume pre- and post-treatment. Treatment with DPTC at $1 \mathrm{mg} / \mathrm{kg} /$ day for 4 weeks led to a 40 percent lowering of left ventricular stiffness, essentially restoring the elasticity of the heart in aged animals to levels seen in much-younger ones (Asif et al., 2000).

The finding that already-formed AGE crosslinks can be pharmacologically severed and attendant pathology thereby reversed has broad implications for the therapeutics of the complications of diabetes and diseases of aging. The prospect of reversing the effects of AGEs was previously only contemplated in the context of stimulating the body's own removal and repair mechanisms. Because of the unique mechanistic aspects of agents like DPTC, further chemical, preclinical, and clinical studies with these AGE-crosslink-breaking agents has the potential to establish new paradigms in the management of diabetes and aging diseases. Such research also will increase the understanding of how AGEs cause pathology and the extent of AGE involvement in the various complications of diabetes and aging, compared to other mechanisms proposed for these processes.

\section{REFERENCES}

Acosta, J., Hettinga, J., Fluckiger, R., Krumrei, N., Goldfine, A., Angarita, L., and Halperin, J. (2000). Proc. Natl. Acad. Sci. U.S.A. 97, 5450-5455.

Ahmed, M.U., Brinkmann Frye, E., Degenhardt, T.P., Thorpe, S.R., and Baynes, J.W. (1997). Biochem. J. 324, 565-570.

Al-Abed, Y., and Bucala, R. (2000). Bioconjug. Chem. 11, 39-45.

Al-Abed, Y., Mitsuhashi, T., Ulrich, P. and Bucala, R. (1996). Bioorg. Med. Chem. Lett. 6, 1577-1578. Antudori, M. (1925). Atti real. accad. naz. Lincei 2, 337.

Asif, M., Egan, J., Vasan, S., Jyothirmayi, G.N., Masurekar, M.R., Lopez, S., Williams, C., Torres, R.L., Wagle, D., Ulrich, P., Cerami, A., Brines, M., and Regan, T.J. (2000). Proc. Natl. Acad. Sci. U.S.A. 97, 2809-2813.

Avendano, G.F., Agarwal, R.K., Bashey, R.I., Lyons, M.M., Soni, B.J., Jyothirmayi, G.N., and Regan, T.J. (1999). Diabetes 48, 1443-1447.

Bach, L.A., Dean, R., Youssef, S., and Cooper, M.E. (2000). Nephrol. Dial. Transplant. 15, 347-354. 
Baynes, J.W., and Thurpe, S.R. (1999). Diabetes 48, 1-9.

Brinkmann Frye, E., Degenhardt, T.P., Thorpe, S.R., and Baynes, J.W. (1998). J. Biol. Chem. 273, 18714-18719.

Brown, C.D., Zhao, Z.H., De Alvaro, F., Chan, S., and Friedman, E.A. (1993). Diabetes 42, 590-593.

Brownlee, M., Pongor, S., and Cerami, A. (1983). J. Exp. Med. 158, 1739-1744.

Brownlee, M., Vlassara, H., Kooney, A., Ulrich, P., and Cerami, A. (1986). Science 232, 1629-1632.

Bucala, R., and Cerami, A. (1995). In "Multiple Risk Factors in Cardiovascular Disease : Vascular and Organ Protection" (A.M. Gotto, Jr. et al., eds.), pp. 155-163. Kluwer Acadernic Publishers, Dordrecht, Netherlands.

Bucala, R., Vlassara, H., and Cerami, A. (1992). In "Post-Translation Modification of Proteins" (J.J. Harding and M.J.C. Crabbe, eds.), pp. 53-79. CRC Press, Inc, Boca Raton, Fla.

Bucala, R., Lee, A.T., Rourke, L., and Cerami, A. (1993a). Proc. Natl. Acad. Sci. U.S.A. 90, 2666-2670

Bucala, R., Makita, Z., Koschinsky, T., Cerami, A., and Vlassara, H. (1993b). Proc. Natl. Acad. Sci. U.S.A. 90, 6434-6438.

Bucala, R., Makita, Z., Koschinsky, T., Cerami, A., and Vlassara, H. (1994). Spec. Publ. R. Soc. Chem. 151, 286-291.

Bucala, R., Mitchell, R., Arnold, K., Innerarity, T., Vlassara, H., and Cerami, A. (1995). J. Biol. Chem. 270, 10828-10832.

Bunn, H.F., Gabbay, K.H., and Gallop, P.M. (1978). Science 200, $21-27$.

Buttner, U., Gerum, F., and Severin, T. (1997). Carbohydr. Res. 300, 265-269.

Cai, J., and Hurst, H.E. (1999). J. Mass Spectrom. 34, 537-543.

Chang, J.C., Ulrich, P.C., Bucala, R., and Cerami, A. (1985). J. Biol. Chem. 260, 7970-7974.

Chen, H.J.C., and Cerami, A. (1993). J. Carbohydr. Chem. 12, 731-742.

Degenhardt, T.P., Thorpe, S.R., and Baynes, J.W. (1998). Cell. Mol. Biol. (Noisy-le-grand) 44, 1139-1145.

Dyer, D.G., Blackledge, J.A., Katz, B.M., Hull, C.J., Adkisson, H.D., Thorpe, S.R., Lyons, T.J., and Baynes, J.W. (1991). Zeitschr. Ernahrungswiss. 30, 29-45.

Ellis, E.N., and Good, B.H. (1991). Metabolism 40, 1016-1019.

Esposito, C., Gerlach, H., Brett, J, Stern, D., and Vlassara, H. (1989). J. Exp. Med. 170, 1387-1407.

Estendorfer, S., Ledl, F, and Severin, T. (1990). Angew. Chem. Int. Ed. Eng 29, 536-537.

Farmar, J.G., Ulich, P.C., and Cerami, A. (1988). J. Org. Chem. 53, 2346-2349.

Glomb, M.A., and Monnier, V.M. (1995). J. Biol. Chem. 270, 10017-10026.

Hammes, H.P., Martin, S., Federlin, K., Geisen, K., and Brownlee, M. (1991). Proc. Natl. Acad. Sci. U.S.A. 88, $11555-11558$.

Harding, J.J. (1973). Exp. Eye Res. 17, 377-383

Hayase, F., Nagaraj. R.H., Miyata, S., Njoroge, F.G., and Monnier, V.M. (1989). J. Biol. Chem. 264, 3758-3764.

Hodge, J.E. (1955). Adv. Carbohydr. Chem. 10, 169-205.

Huber, B., and Ledl, F. (1990). Carbohydr. Res. 204, 215-220.

Huijberts, M.S., Wolffenbuttel, B.H., Boudier, H.A., Crijns, F.R., Kruseman, A.C., Poitevin, P., and Levy, B.I. (1993). J. Clin. Invest. 92, 1407-1411.

Kihara, M., Schmelzer, J.D., Poduslo, J.F., Curran, G.L., Nickander, K.K., and Low, P.A. (1991). Proc. Natl. Acad. Sci. U.S.A. 88, 6107-6111.

Klein, E., Ledl, F, Bergmuller, W., and Severin, T. (1992). Z. Lebensm. Unters. Forsch. 194, 556-560.

Knecht, K.J., Dunn, J.A., McFarland, K.F., McCance, D. R., Lyons, T.J., Thorpe, S.R., and Baynes, J.W. (1991). Diabetes 40, 190-196.

Knerr, T., and Severin, T. (1993). Tetrahedron Lett. 46, 7389-7390.

Knerr, T., Ochs, S., and Severin, T. (1994). Carbohydr. Res. 256, 177-183.

Koenig, R.J., Peterson, C.M., Jones, R.L., Saudek, C., Lehrman, M., and Cerami, A. (1976). N. Engl. J. Med. 295, 417-420. 
Koenig, R.J., Blobstein, S.H., and Cerami, A. (1977). J. Biol. Chem. 252, 2992-2997.

Kohn, R.R., Cerami, A., and Monnier, V.M. (1984). Diabetes 33, 57-59.

Koschinsky, T., He, C.J., Mitsuhashi, T., Bucala, R., Liu, C., Buenting, C., Heitmann, K., and Vlassara, H. (1997). Proc. Natl. Acad. Sci. U.S.A. 94, 6474-6479.

Krook, M., Ghosh, D., Stromberg, R., Carlquist, M., and Jornvall, H. (1993). Proc. Natl. Acad. Sci. U.S.A. 90, 502-506.

Lederer, M.O., and Klaiber, R.G. (1999). Bioorg. Med. Chem. 7, 2499-2507.

Lee, A.T., and Cerami, A. (1987). Mutat. Res. 179, 151-158.

Lee, A.T., and Cerami, A. (1990). Mutat. Res. 238, 185-191.

Lee, A.T., and Cerami, A. (1991). Mutat. Res. 249, 125-133.

Lee, A.T., Plump, A., DeSimone, C., Cerami, A., and Bucala, R. (1995). Diabetes 44, $20-24$.

l.iardon, R., de Weck-Gaudard, D., Philippossian, G., and Finot, P.A. (1987). J. Agric. Food Chem. 35, 427-431.

Maillard, L.C., and Gautier, M.A. (1912). C. R. Seances Acad. Sci. III 154, 66-68.

Makita, Z., Radoff, S., Rayfield, E.J., Yang, Z., Skolnik, E., Delaney, V., Friedman, E.A., Cerami, A., and Vlassara, H. (1991). N. Engl. J. Med. 325, 836-842

Makita, Z., Vlassara, H., Cerami, A., and Bucala, R. (1992). J. Biol. Chem. 267, 5133-5138.

Miyauchi, Y., Shikama, H., Takasu, T., Okamiya, H., Umeda, M., Hirasaki, E., Ohhata, I., Nakayama, H., and Nakagawa, S. (1996). Eur. J. Endocrinol. 134, 467-473.

Monnier, V.M., and Cerami, A. (1981). Science 211, 491-493.

Monnier, V.M., and Cerami, A. (1983). Biochim. Biophys. Acta 760, 97-103.

Monnier, V.M., Stevens, V.J., and Cerami, A. (1979). J. Exp. Med. 150, 1098-1107.

Nadkarni, D.V., and Sayre, L.M. (1995). Chem. Res. Toxicol. 8, 284-291.

Nakayama, H., Kato, M., Makita, Z., Aoki, S., Kuroda, Y., Misawa, K., Yanagisawa, K., Nakagawa, S., and Ikeda, K. (1988). J. Immunol. Meth. 112, 57-61.

Nissl, J., Pischetsrieder, M., Klein, E., and Severin, T. (1995). Carbohydr. Res. 270, C1-C5.

Niwa, T. (1999). J. Chromatogr. B Biomed. Sci. Appl. 731, 23-36.

Niwa, T., Katsuzaki, T., Ishizaki, Y., Hayase, F., Miyazaki, T., Uematsu, T., Tatemichi, N., and Takei, Y. (1997). FEBS Lett. 407, 297-302.

Njoroge, F.G., Fernandes, A.A., and Monnier, V.M. (1988). J. Biol. Chem. 263, 10646-10652

Obayashi, H., Nakano, K., Shigeta, H., Yamaguchi, M., Yoshimori, K., Fukui, M., Fujii, M., Kitagawa, Y., Nakamura, N., Nakamura, K., Nakazawa, Y., lenaga, K., Ohta, M., Nishimura, M., Fukui, 1., and Kondo, M. (1996). Biochem. Biophys. Res. Commun. 226, 37-41.

Palinski, W., Koschinsky, T., Butler, S. W., Miller, E., Vlassara, H., Cerami, A., and Witztum, J. L. (1995). Arterioscler. Thromb. Vasc. Biol. 15, 571-582.

Panagiotopoulos, S., O'Brien, R.C., Bucala, R., Cooper, M.E., and Jerums, G. (1998). Atherosclerosis 136, 125-131.

Papoulis, A., Al-Abed, Y., and Bucala, R. (1995). Biochemistry 34, 648-655.

Paul, R.G., Avery, N.C., Slatter, D.A., Sims, T.J., and Bailey, A.J. (1998). Biochem. J. 330, 1241-1248.

Paulsen, H., and Pflughaupt, K.W. (1980). In "The Carbohydrates: Chemistry and Biochemistry," edit. 2, vol lB (W. Pigman and D. Horton, eds.), pp. 881-927. Academic Press, New York.

Pongor, S., Ulrich, P.C., Bencsath, F.A., and Cerami, A. (1984). Proc. Natl. Acad. Sci. U.S.A. 81, 2684-2688.

Roufail, E., Soulis, T., Boel, E., Cooper, M.E., and Rees, S. (1998). Diabetologia 41, 1419-1425.

Sell, D.R., Nagaraj, R.H., Grandhee, S.K., Odetti, P., Lapolla, A., Fogarty, J., and Monnier, V.M. (1991). Diabetes Metab. Rev. 7, 239-251

Shapiro, R., Cohen, B.I., Shiuey, S.J., and Maurer, H. (1969). Biochemistry 8, 238-245.

Sims, T.J., Rasmussen, L.M., Oxlund, H., and Bailey, A.J. (1996). Diabetologia 39, 946-951

Skolnik, E.Y., Yang, Z., Makita, Z., Radoff, S., Kirstein, M., and Vlassara, H. (1991). J. Exp. Med. 174, 931-939. 
Soulis-Liparota, I., Cooper, M., Papazoglou, D., Clarke, B., and Jerums, G. (1991). Diabetes 40, 1328-1334.

Tessier, F., Obrenovich, M., and Monnier, V.M. (1999). J. Biol. Chem. 274, 20796-20804.

Thornalley, P.J., I anghorg, A, and Minhas, H.S (1999). Biochem. J. 344, 109-116.

Vasan, S., Zhang, X., Kapurniotu, A., Bernhagen, J., Teichberg, S., Basgen, J., Wagle, D., Shih, D., Terlecky, I., Bucala, R., Cerami, A., Egan, J, and Ulrich, P. (1996). Nature 382, 275-278.

Vitek, M.P., Bhattacharya, K., Glendening, J.M., Stopa, E., Vlassara, H., Bucala, R., Manogue, K., and Cerami, A. (1994). Proc. Natl. Acad. Sci. U.S.A. 91, 4766-4770.

Vlassara, H., Brownlee, M., Manogue, K.R., Dinarello, C.A., and Pasagian, A. (1988). Science 240, 1546-1548.

Vlassara, H., Fuh, H., Makita, Z., Krungkrai, S., Cerami, A., and Bucala, R. (1992). Proc. Natl. Acad Sci. U.S.A. 89, $12043-12047$.

Witztum, J.L., and Steinberg, D. (1991). J. Clin. Invest. 88, 1785-1792.

Wolffenbuttel, B.H., Boulanger, C.M., Crijns, F.R., Huijberts, M.S., Poitevin, P., Swennen, G.N., Vasail, S., Egan, J.J., Ulrich, P., Cerami, A., and Levy, B.I. (1998), Proc. Natl. Acad. Sci. U.S.A. 95, 4630-4634.

Yue, D.K., McLennan, S., Delbridge, L., Handelsman, D.J., Reeve, T., and Turtle, J.R. (1983). Diabetologia 24, 282-285. 
